Sādhanā Vol. 40, Part 7, October 2015, pp. 2197-2220. (C) Indian Academy of Sciences

\title{
Effects of PCB thickness on adjustable fountain wave soldering
}

\author{
M S ABDUL AZIZ ${ }^{1, *}$, M Z ABDULLAH ${ }^{1}, \mathrm{C} \mathrm{Y} \mathrm{KHOR}^{2}$, \\ $\mathrm{A} \mathrm{JALAR}^{3}, \mathrm{M} \mathrm{A} \mathrm{BAKAR}^{3}, \mathrm{~W}$ Y W YUSOFF${ }^{3}, \mathrm{~F} \mathrm{CHE} \mathrm{ANI}^{4}$, \\ NOBE YAN ${ }^{5}, \mathrm{M} \mathrm{ZHOU}^{5}$ and $\mathrm{C} \mathrm{CHEOK}^{6}$ \\ ${ }^{1}$ School of Aerospace Engineering, Universiti Sains Malaysia, \\ Engineering Campus, 14300 Nibong Tebal, Penang, Malaysia \\ ${ }^{2}$ Faculty of Engineering Technology (FETech), Universiti Malaysia Perlis (UniMAP), \\ Kampus UniCITI Alam, Sungai Chuchuh, Padang Besar, 02100 Perlis, Malaysia \\ ${ }^{3}$ Institute of Microengineering and Nanoelectronics, University Kebangsaan \\ Malaysia, 43600 Bangi, Selangor, Malaysia \\ ${ }^{4}$ Jabil Circuit Sdn. Bhd., Bayan Lepas Industrial Park, 11900 Bayan Lepas, Penang, \\ Malaysia \\ ${ }^{5}$ Shenzhen Kunqi Xinhua Technology Co., Ltd, Gangtou, Bantian, Longgang, \\ Shenzhen, Guangdong, China \\ ${ }^{6}$ Cyntac Pte. Ltd., 32 Ang Mo Kio Industrial Park 2, Singapore, Singapore \\ e-mail: sharizalaziz1983@gmail.com
}

MS received 8 July 2014; revised 25 March 2015; accepted 11 May 2015

\begin{abstract}
This study investigates the effects of printed circuit board (PCB) thickness on adjustable fountain and conventional wave soldering. The pin-through-hole (PTH) vertical fill is examined with three PCBs of different thicknesses (i.e., 1.6, 3.1, and $6.0 \mathrm{~mm}$ ) soldered through adjustable fountain and conventional wave soldering at conveyor angles of $0^{\circ}$ and $6^{\circ}$. The vertical fill of each PCB is the focus. The PTH solder profile is inspected with a non-destructive X-ray computed tomography scanning machine. The percentages of the PTH vertical fill of both soldering processes are also estimated and compared. The aspect ratio of the PCB is also investigated. Experimental results reveal that adjustable fountain wave soldering yields better vertical fill than conventional wave soldering. The vertical fill level of adjustable fountain wave soldering is $100 \%, 90 \%$, and $50 \%$ for the 1.6, 3.1, and $6.0 \mathrm{~mm}$ PCB thickness, respectively. FLUENT simulation is conducted for the vertical fill of the solder profile. Simulation and experimental results show that the PTH solder profiles of the two soldering processes are almost identical. The effect of PCB thickness on PTH voiding is also discussed.
\end{abstract}

Keywords. Pin through hole (PTH); adjustable fountain wave soldering; wave soldering; printed circuit board (PCB); vertical fill; simulation.

*For correspondence 


\section{Introduction}

Wave soldering is widely utilized to solder pin-through-hole (PTH) components onto printed circuit boards (PCB) in the electronics assembly industry. Typical PTH components, such as microcontrollers, resistors, capacitors, IC sockets, and pin connectors, are fixed on PCBs through wave soldering. Prior to wave soldering, the bottom surface of PCBs is sprayed with flux to remove any oxide layers on the PCB and pin. The PCB is then pre-heated to a desired temperature to activate the flux and prevent thermal shock. The PCB is placed over a solder pot. The waveform molten solder and the bottom surface of the PCB are placed into contact with each other, and the molten solder fills the PCB hole through a capillary action. The filled PCB hole solidifies and forms a solder joint at the cooling zone. An insufficient vertical fill, usually less than $75 \%$, is considered defective according to IPC-A-610D (IPC 2005).

Many studies have been conducted on wave soldering and its various aspects, including its material and mechanical characteristics (Kuo et al 2013), PTH defects (Suganuma et al 2000), low silver alloy (Wang et al 2013), the intelligence system of the process control (Pietraszek et al 2014; Liukkonen et al 2009), and process optimization (Liukkonen et al 2011; Huang et al 2012). Most of these studies were conducted through experiments. The type of solder material used significantly affects the reliability of a PTH solder joint. The use of $\mathrm{Sn}-0.7 \mathrm{Cu}-0.05 \mathrm{Ni}$ as a solder material can improve the tensile strength of PTH (Kuo et al 2013). However, PTH lift-off (Suganuma et al 2000) occurs at the top of the PCB when Sn-Bi alloy is utilized. The presence of anti-oxidation elements in a low-silver lead-free solder material enhances oxidation resistance but causes poor wettability (Wang et al 2013). Defects in the solder joints are always a problem for engineers in the electronics assembly industry. Thus, an intelligence system (Pietraszek et al 2014; Liukkonen et al 2009) has been developed and employed to identify defects and determine their dominant process parameters during wave soldering. Process optimization (Liukkonen et al 2011; Huang et al 2012; Wang et al 2011) (i.e., self-organizing maps and multivariate analysis) has also been employed to control the quality and reliability of PTH solder joints during wave soldering.

Tiny PTH and limited equipment have created difficulties in visualizing the real-time PTH filling process. Simulation modeling technique helps engineers understand the process of PTH filling. Simulation tools, such as OpenFOAM (Inagaki et al 2013) and FLUENT (Abdul Aziz et al 2013), have been employed in various studies on the wave soldering process. Such studies focused on the vertical filling of the PCB hole. The flow behavior of the molten solder was simulated and visualized with a simulation tool in these studies. For example, Inagaki et al (2013) investigated the dynamic movement of the molten solder through a simple 2D model. Abdul Aziz et al (2013, 2014c) employed CFD modeling and FLUENT to simulate the capillary flow in wave soldering. The effects of pin offset (Abdul Aziz et al 2013) and shape (Abdul Aziz et al 2014c) on the filling mechanism were investigated numerically through a 3D model. The simulation analysis was extended through thermal coupling method Abdul Aziz et al 2014a, b). The thermal-induced displacement, stress, and temperature of the pin were also discussed based on the simulation results. Vertical fill and the solder profile are influenced by PTH diameter and offset angle. Aside from the process parameters, the optimized PCB hole and PTH design are also important factors that influence the vertical fill during wave soldering. 


\section{Problem statement}

The vertical fill of a PCB hole is always a concern in the electronics assembly process. A vertical fill of less than $75 \%$ is considered defective in most applications. However, a vertical fill of $50 \%$ is acceptable under specific conditions when PTH is connected to thermal or conductor layers that function as thermal heat sinks (IPC 2005). An increase in PCB thickness may affect the percentage of vertical fill during wave soldering. Conventional wave soldering machines (e.g., single or dual soldering pot) are typically utilized in the industry. Although wave soldering technology is well established, the vertical fill of the PCB hole still requires proper process control. Several conditions, such as an unstable waveform, insufficient waveform height, improper dwell time, and preheating temperature, may affect the performance of the vertical fill. The adjustable fountain wave soldering machine was developed to enhance the wave soldering process. The fountain waveform is generated from the pressure nozzle of the machine. In the current study, PCBs with various thicknesses are soldered with adjustable fountain ( $0^{\circ}$ conveyor angle) and conventional $\left(6^{\circ}\right.$ conveyor angle) wave soldering machines.

\section{Experimental setup}

In the electronics assembly industry, wave soldering has numerous functions, such as component hybrid circuit assembly, component lead tinning, and wire tinning. However, it is mainly utilized to solder of circuit board assemblies. PTH components, such as the pin, resistor, and light emitting diode, are inserted into the PCB hole and carried by the conveyor to the soldering zone. The soldering process begins when a mechanical bond is formed between PTH and the PCBs passing through the molten solder. This study investigated the effect of PCB thickness on the vertical fill of the PCB hole. Three PCBs with different thicknesses (1.6, 3.1, and $6.0 \mathrm{~mm}$ ) and $100 \mathrm{sam}$ ples of PTH were utilized as shown in figure 1 . The PCB dimensions were $120 \mathrm{~mm} \times 80 \mathrm{~mm} \times$ $1.6 \mathrm{~mm}$ (figure 2(a)). Two types of PTH shape (i.e., circle and square) were assembled onto the PCBs as shown in figure 2(b).

Wave soldering experiments were performed with a conventional wave soldering machine (figure 3 ) and the proposed adjustable fountain wave soldering machine to investigate the vertical

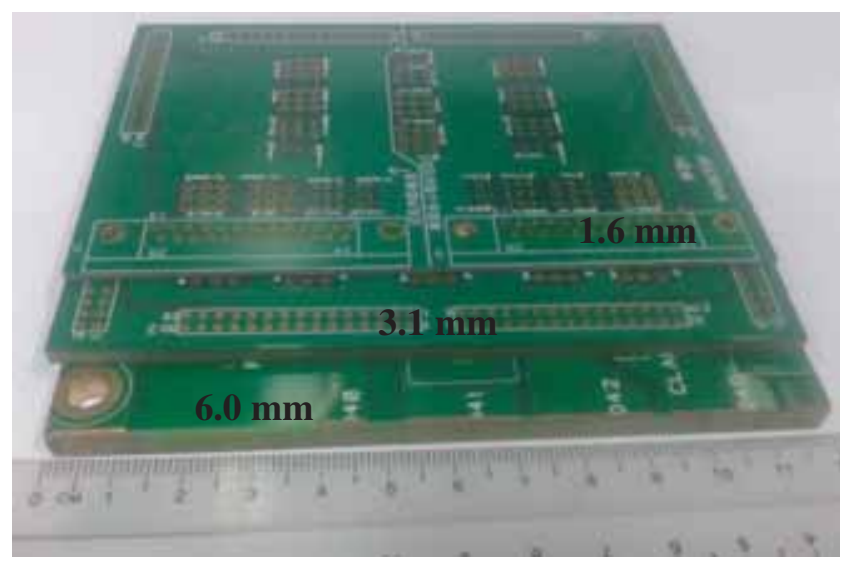

Figure 1. PCBs at different thicknesses $(1.6 \mathrm{~mm}<t<6.0 \mathrm{~mm})$ used for adjustable fountain and conventional wave soldering process. 


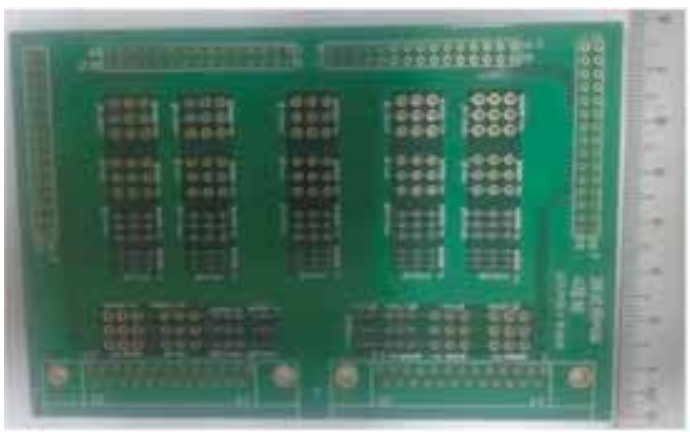

(a)

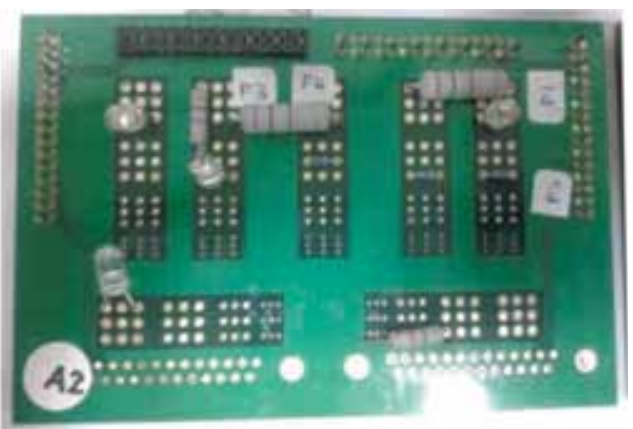

(b)

Figure 2. Sample of PCB used for adjustable fountain and conventional wave soldering process. (a) Plain PCB; (b) PCB with PTH components.

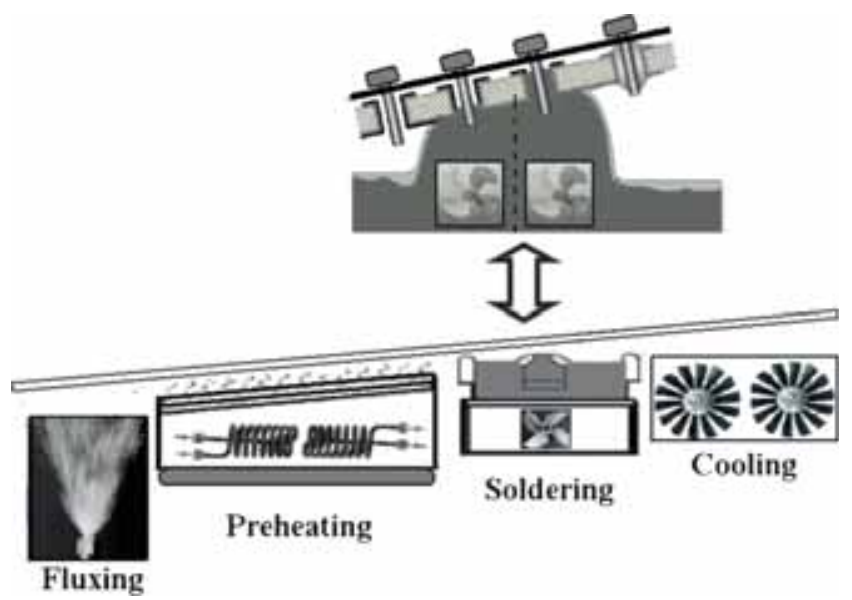

Figure 3. Schematic diagram of the conventional wave-soldering machine.

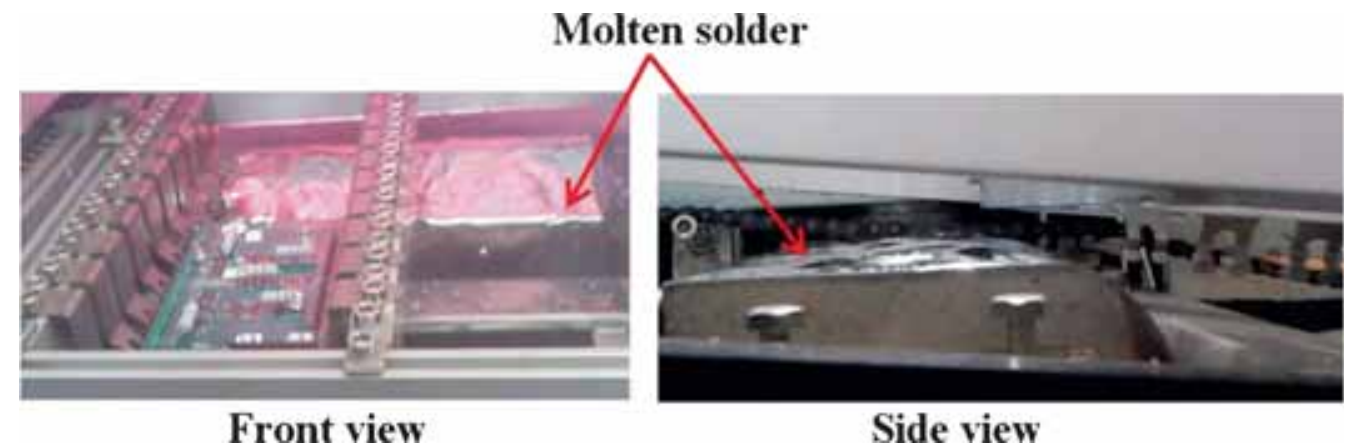

Figure 4. Laminar and chip wave of the conventional wave-soldering machine.

fill of the molten solder in the PCB hole. A Sn63Pb37 solder was utilized, and the soldering zone of both machines was set to $250^{\circ} \mathrm{C}$. The PCB and PTH components were assembled at a conveyor angle inclination of $6^{\circ}$ in four process zones (i.e., fluxing, preheating, soldering, and 

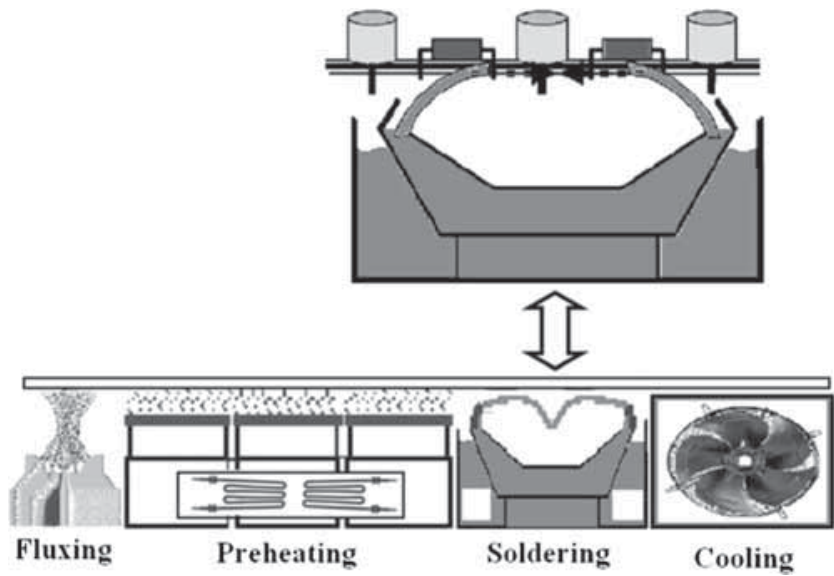

Figure 5. Schematic diagram of the adjustable fountain wave-soldering machine.
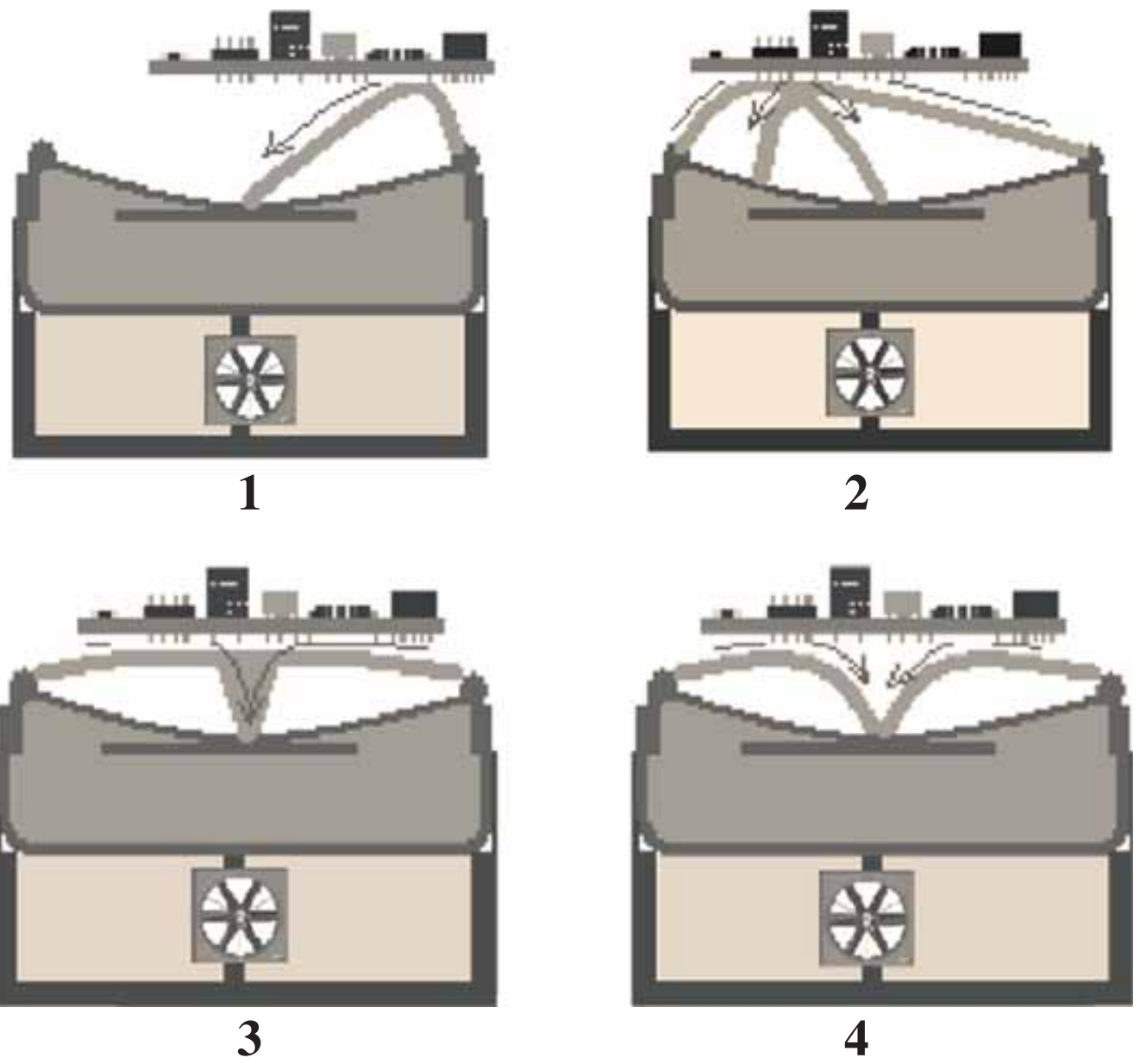

Figure 6. Schematic illustration of adjustable pressure nozzles for the adjustable fountain wave-soldering machine. 
cooling zones). In the fluxing zone, the bottom of the PCB was sprayed with flux using an opennozzle sprayer with air pressure. The PCB was then subjected to an open-type preheating system in the preheating zone. The sensor of the propeller (at the soldering zone) was activated after the PCB passed the preheating zone. The laminar and chip waves of the molten solder generated by the propeller (figure 4) soldered the PCB and PTH components. Finally, the PCB was transferred to the cooling zone for cooling and solidification.

In the newly developed fountain wave soldering machine (figure 5), the PCB was inclined at a conveyor angle of $0^{\circ}$. An ultrasonic atomizing flux spraying system was introduced in the fluxing zone to allow for denser and more uniform fluxing than that in the open nozzle of conventional fluxing spray technique. The PCBs were then conveyed to the closed-type preheating system of the preheating zone. Unlike the open-type preheating system in the conventional wave soldering machine, this system controls the heat distribution to the PCB and reduces the heat that is usually lost to the environment. The PCB was then conveyed to the closed soldering zone. The new adjustable fountain wave soldering machine is equipped with adjustable pressure nozzles (figure 6), which were used to induce high energy from the molten solder to the PCB by adjusting the air pressure. The molten solder rises and fills the space between the PCB hole and PTH at a certain vertical filling level. Figure 7 shows the fountain wave generated from the pressure nozzles. The filled PCB holes were solidified at the cooling zone.

The vertical filling of solder joints was examined with the non-destructive X-ray CT scanning machine of the Institute of Microengineering and Nanoelectronics, University Kebangsaan Malaysia, Malaysia. This machine was utilized because of its capacity to produce tomography images of the specific soldered vertical fill without any damage. Figure 8 shows the X-ray CT scan and sample of the PCB with PTH after wave soldering. Three-dimensional images of the height of the vertical fill (from the bottom to the top of PTH) were obtained and void formation in the solder joint was determined through digital geometry processing. The solder profiles of the adjustable fountain wave soldering machine at vertical fills of 50\%, 75\%, and $100 \%$ were compared with those in the simulation results.

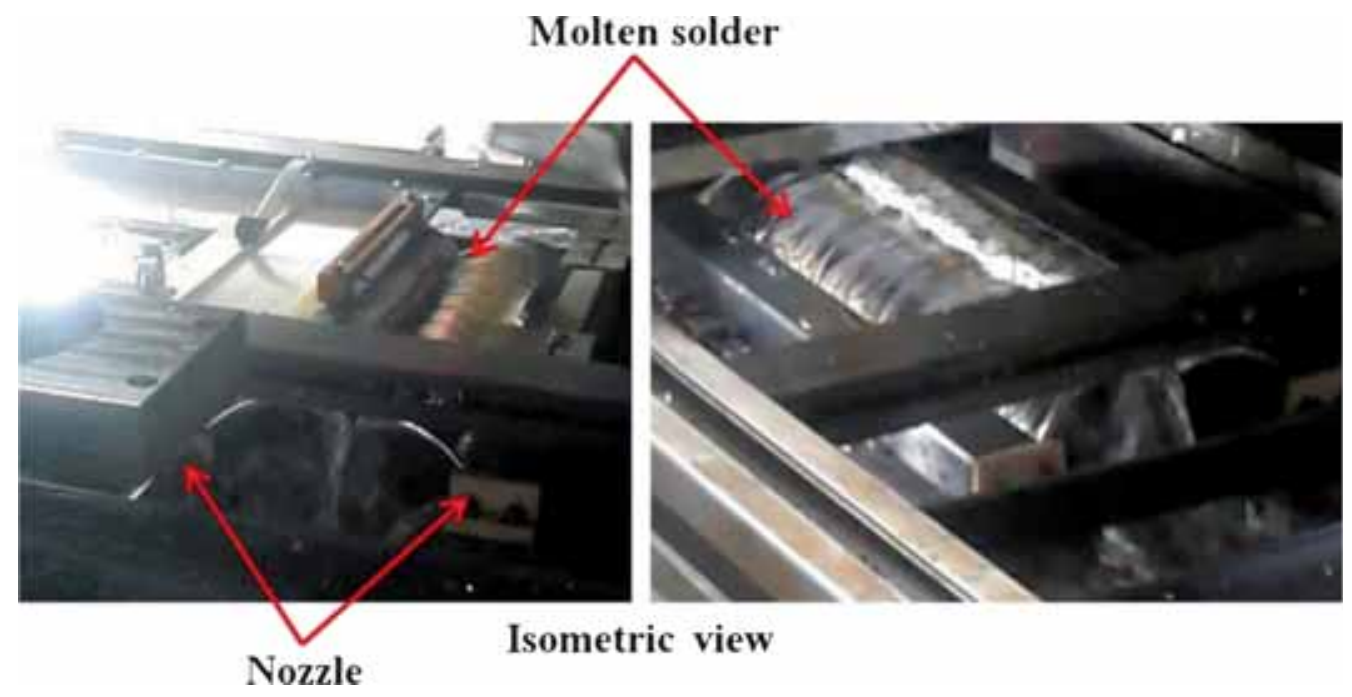

Figure 7. Generated fountain wave solder from the pressure nozzles. 


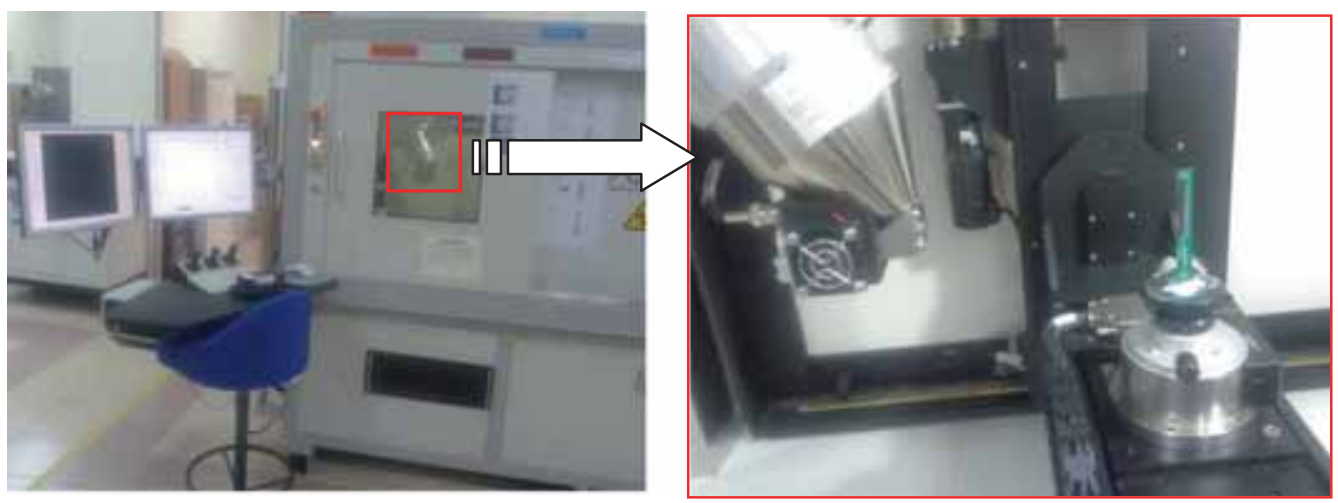

Figure 8. X-Ray CT scanning machine and specimen of PCB with PTHs.

\section{Governing equations}

In the wave soldering process, after the molten solder interacted with the bottom surface of the PCB, the capillary effect drives the molten solder to fill the space. The motion of capillary flow in the PCB hole is described by the governing equations. The capillary flow was modeled by using the commercial FVM simulation software FLUENT (Yapici et al 2005). The molten solder and air were considered as two different phases. The 3D fluid motions were assumed to be incompressible and were described by the conservation of mass, momentum, and energy as follows:

Continuity equation:

$$
\frac{\partial u}{\partial x}+\frac{\partial v}{\partial y}+\frac{\partial w}{\partial z}=0
$$

where $u, v$, and $w$ are the velocity in the $x-, y$-, and $z$-axis, respectively.

Momentum equation (Ramdan et al 2012):

$x$-direction

$$
\frac{\partial u}{\partial t}+u \frac{\partial u}{\partial x}+v \frac{\partial u}{\partial y}+w \frac{\partial u}{\partial z}=-\frac{1}{\rho} \frac{\partial P}{\partial x}+\eta\left[\frac{\partial}{\partial x}\left(\frac{\partial u}{\partial x}\right)+\frac{\partial}{\partial y}\left(\frac{\partial u}{\partial y}\right)+\frac{\partial}{\partial z}\left(\frac{\partial u}{\partial z}\right)\right]+\rho g_{x}
$$

$y$-direction

$$
\frac{\partial v}{\partial t}+u \frac{\partial v}{\partial x}+v \frac{\partial v}{\partial y}+w \frac{\partial v}{\partial z}=-\frac{1}{\rho} \frac{\partial P}{\partial y}+\eta\left[\frac{\partial}{\partial x}\left(\frac{\partial v}{\partial x}\right)+\frac{\partial}{\partial y}\left(\frac{\partial v}{\partial y}\right)+\frac{\partial}{\partial z}\left(\frac{\partial v}{\partial z}\right)\right]+\rho g_{y}
$$

$z$-direction

$$
\frac{\partial w}{\partial t}+u \frac{\partial w}{\partial x}+v \frac{\partial w}{\partial y}+w \frac{\partial w}{\partial z}=-\frac{1}{\rho} \frac{\partial P}{\partial w}+\eta\left[\frac{\partial}{\partial x}\left(\frac{\partial w}{\partial x}\right)+\frac{\partial}{\partial y}\left(\frac{\partial w}{\partial y}\right)+\frac{\partial}{\partial z}\left(\frac{\partial w}{\partial z}\right)\right]+\rho g_{z} .
$$

Energy equation:

$$
\rho c_{p}\left(\frac{\partial T}{\partial t}+u \frac{\partial T}{\partial x}+v \frac{\partial T}{\partial y}+w \frac{\partial T}{\partial z}\right)=k\left(\frac{\partial^{2} T}{\partial x^{2}}+\frac{\partial^{2} T}{\partial y^{2}}+\frac{\partial^{2} T}{\partial z^{2}}\right) .
$$


Molten solder at high temperature has a nearly constant viscosity (Puttlitz \& Stalter 2004) and can thus be described as follows:

Newtonian fluid equation:

$$
\eta=\frac{\tau}{\dot{\gamma}}
$$

where $\tau$ is the shear stress and $\dot{\gamma}$ is the strain rate.

The volume of fluid (VOF) tracks the flow front during the wave soldering process. The governing equation of melt front over time is governed by the following transport equation (Ramdan et al 2012):

$$
\frac{d F}{d t}=\frac{\partial F}{\partial t}+\nabla \cdot(u F)=0,
$$

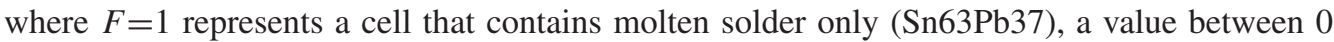
and $1(0<F<1)$ is given in "interface" cells (referred to as melt front of the molten solder), and $F=0$ represented in a grid of molten solder void.

\section{FLUENT modeling}

A simulation was performed prior to the experimental study to validate the feasibility of the experimental evaluation by comparing the experimental and simulation results. In the experiment, the visualization of the real time PCB hole filling process is difficult due to the tiny size and limited equipment. Therefore, the simulation modeling technique is advantageous to provide the process visualization. Thus, the purpose of simulation analysis is to enrich the understanding of the fluid motion and capillary action of the molten solder. The predicted simulation results are useful for the reference and provide the fundamental knowledge during the wave soldering process. Better understandings of the wave soldering process help the engineer to enhance the process parameter and $\mathrm{PCB}$ design, which could minimize the unintended features and defects of the PTH solder joint. A fluid domain of PTH and PCB was modeled in the pre-processing step. The simulation was conducted for a single pin soldered into the PCB hole using the adjustable fountain wave soldering machine at a conveyor angle of $0^{\circ}$. A 3D model was developed, and the meshing and boundary conditions were set by a preprocessor commercial modeling software according to the actual dimensions of the PCB and PTH mentioned in Section 3. The mesh model was built and optimized with 599920 hybrid nodes as shown in figure 9 . The bottom and sides of the solder pot, PCB hole, and PTH connector were defined as walls in the boundary condition setup. The top of the solder pot was set as the pressure inlet, whereas the top and bottom of the PCB were defined as the interior and pressure outlet (figure 10). The boundary and initial conditions were as follows.

(a) On the PCB, the solder pot and components wall: $u=v=w=0, \frac{\partial P}{\partial n}=0$

(b) On the melt front: $P=P_{a t m}-\Delta P$

(c) At the outlet: $P_{\text {out }}=P_{\text {atm }}=0$

Note: Pressure difference $(\Delta P)$ can be expressed by the law of Young and Laplace. $\Delta P$ is the pressure difference between the inside and outside of the curved liquid surface, $\gamma$ is the liquid surface tension, and $R_{1}$ and $R_{2}$ are the radii of the curvature on liquid surface. Note that $R_{1}$ an $R_{2}$ are negative because they are outside the liquid.

$$
\Delta P=\gamma\left(\frac{1}{R_{1}}+\frac{1}{R_{2}}\right) \text {. }
$$




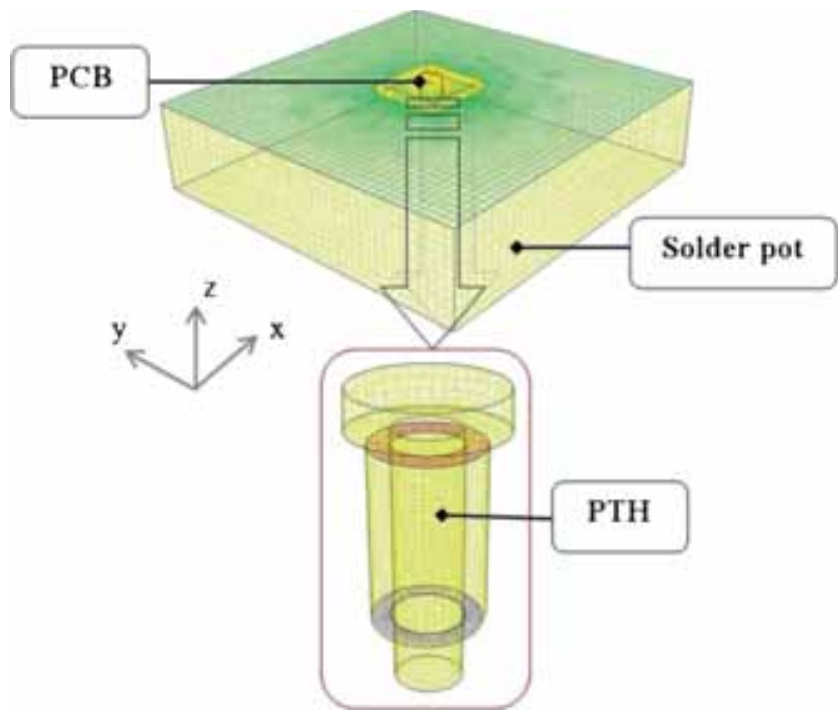

Figure 9. Meshed model.

The developed model was exported to FLUENT for fluid analysis. The optimized time-step size employed in the current simulation was $0.0001 \mathrm{~s}$ (Abdul Aziz et al 2014b). Transient/unsteady calculations were performed in the analysis. A capillary action occurred when the molten solder came into contact with the PCB hole through the soldering process. An implicit VOF method was conducted to track the fluid motions of the two phases (i.e., molten solder and air). The volume fraction was set to 1 for the molten solder and 0 for the air phase. In addition, eutectic Sn63Pb37 was selected as the solder material because of its excellent wetting capability at a low melting temperature $\left(183^{\circ} \mathrm{C}\right)$. The material properties are summarized in table 1 . A uniform temperature of $250^{\circ} \mathrm{C}$ was defined as the initial temperature in FLUENT according to the experimental setup.

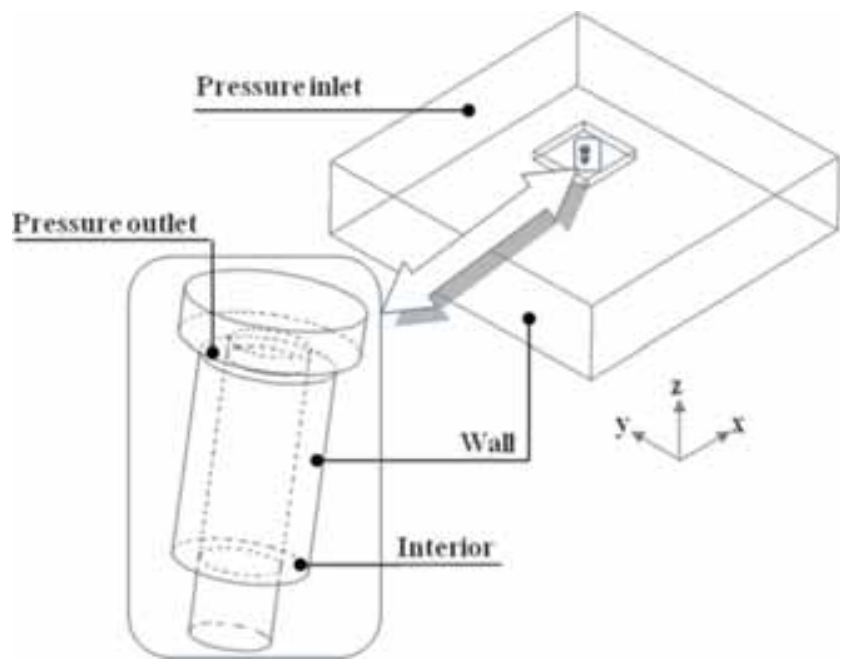

Figure 10. Boundary conditions setup in the FLUENT modeling. 
Table 1. Summarized of eutectic $\mathrm{Sn} 63 \mathrm{~Pb} 37$ properties (Abdul Aziz et al 2014c).

\begin{tabular}{lc}
\hline Factor & Value \\
\hline Viscosity $(\mathrm{mPa} s)$ & 140 \\
Thermal conductivity $(\mathrm{W} / \mathrm{m} \mathrm{K})$ & 50 \\
Specific heat capacity, $C_{p}(\mathrm{~J} / \mathrm{kg} \mathrm{K})$ & 167 \\
Density $\left(\mathrm{kg} / \mathrm{m}^{3}\right)$ & 8400 \\
Reference temperature $\left({ }^{\circ} \mathrm{C}\right)$ & 250 \\
\hline
\end{tabular}

The stability of the melt front was controlled by the following under-relaxation factors: momentum $=0.01$, density $=1.0$, body forces +1.0 , and pressure $=0.3$ (Abdul Aziz et al 2014c). Semi-Implicit Method for Pressure Linked Equations (SIMPLE) algorithm was defined under pressure velocity coupling with the second-order upwind scheme to solve the governing equations and discretize the volume fraction and momentum and energy equations (Abdul Aziz et al 2014c). The simulation results were then compared with the experimental results.

\section{Results and discussion}

\subsection{Validation of the experimental and simulation solder profiles}

Figure 11 shows a comparison of the solder profiles from the experimental and simulation results of PTH. Vertical filling levels of 50\%, 75\%, and $100 \%$ were considered in the adjustable fountain wave soldering process $\left(0^{\circ}\right.$ conveyor angle) for a $3.1 \mathrm{~mm}$ thick PCB. The experimental solder profile was examined through X-ray CT scanning as previously mentioned. The experimental results showed almost uniform solder profiles for each filling level. A slightly convex profile was observed at $75 \%$ filling level. A similar phenomenon was also observed in the simulation results ( $75 \%$ filling level). This occurrence may be attributed to the variation in surface tension in the PCB hole. In the VOF model, a volume fraction of 0.5 (Khor et al 2012a, 2012b; Balachandran 2012; Yazdi et al 2010) is always employed to define the interface of the molten solder. The maximum and minimum levels of the molten solder were estimated for both results and are shown in figure 12. The experimental and simulation results are in reasonable agreement, with only $4.96 \%$ and $2.08 \%$ discrepancies for the maximum and minimum levels, respectively (figures 13 and 14).

\subsection{Effect of PCB thickness}

The effect of PCB thickness on the vertical fill for both adjustable fountain $\left(0^{\circ}\right.$ conveyor angle) and conventional ( $6^{\circ}$ conveyor angle) wave soldering processes was investigated. The vertical fill for the square pin was considered. Figure 15 shows a comparison of the three selected samples for both wave soldering processes at three different PCB thicknesses (i.e., 1.6, 3.1, and 6.0 $\mathrm{mm}$ ). The vertical fill of the PCB hole was observed through X-ray CT scanning. The solder material showed an intense color in the X-ray image. The experimental results revealed that PCB thickness significantly affects the vertical fill in both wave soldering processes. An increase in PCB thickness decreases the vertical fill. The samples of the vertical fill of each PCB thickness are summarized in tables 2 and 3. In the adjustable wave soldering process, the vertical fill was $100 \%$ (with a topside fillet) at $1.6 \mathrm{~mm}$ PCB thickness. Almost $85 \%$ of the PCB hole were filled 

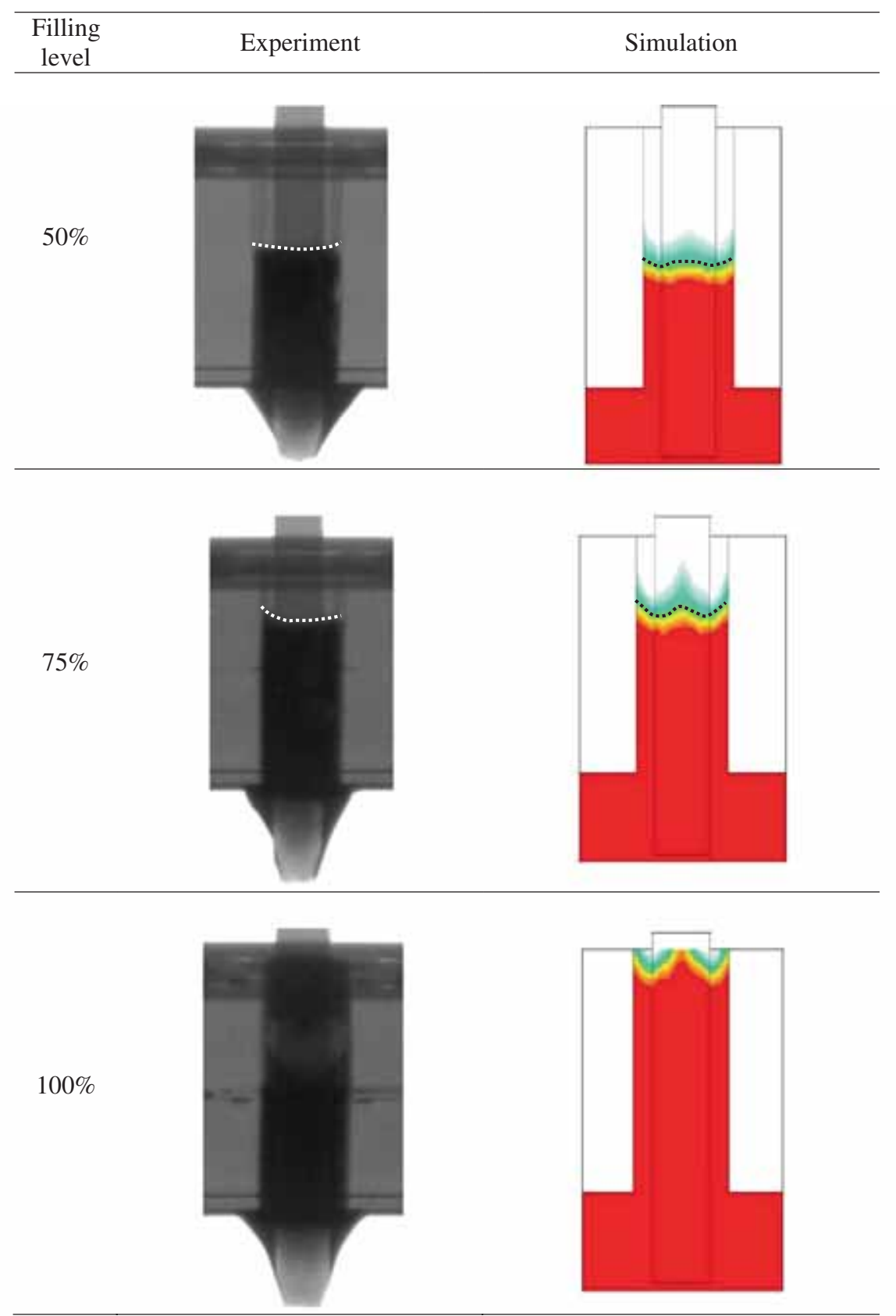

Volume Fraction, $F$

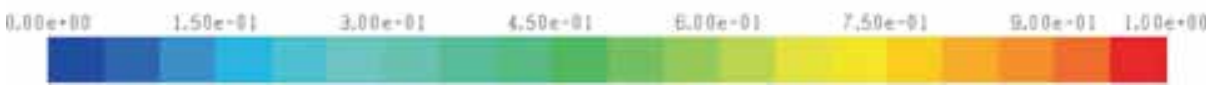

Figure 11. Comparison of experimental and simulation solder profile at 50\% and $75 \%$ and $100 \%$ filling level ( $0^{\circ}$ conveyor angle and $3.1 \mathrm{~mm}$ PCB thickness). 


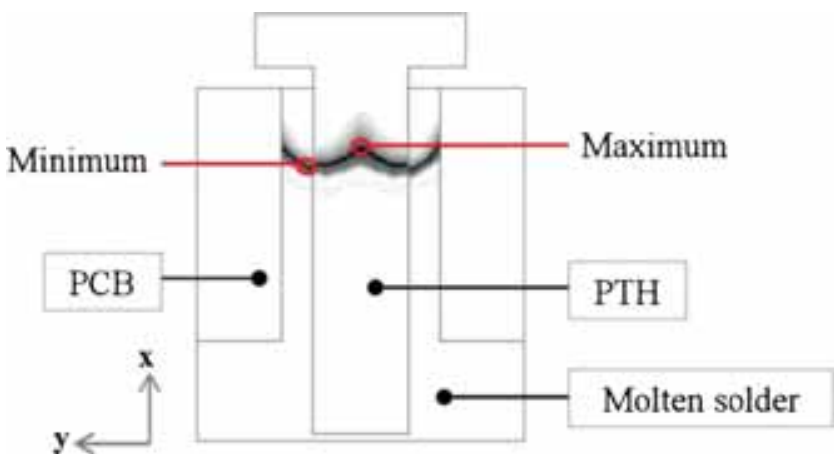

Figure 12. Maximum and minimum filling level.

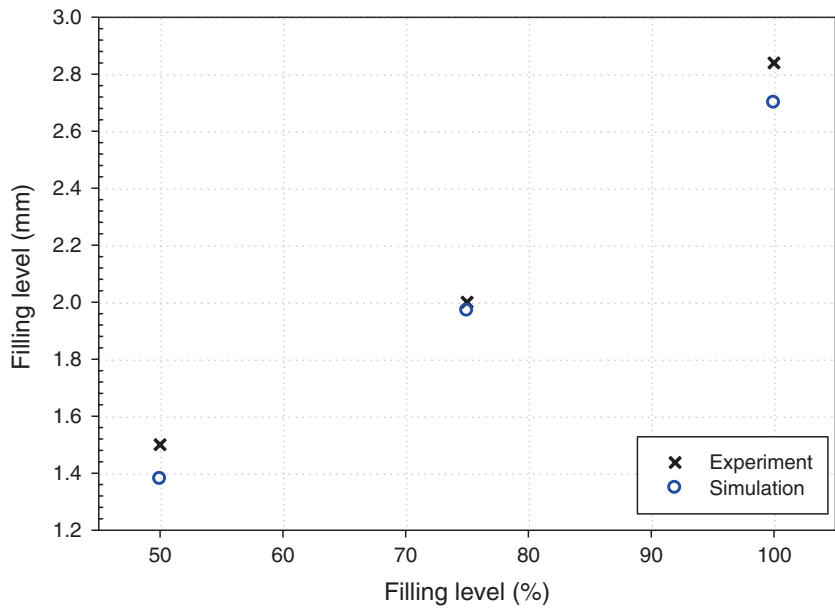

Figure 13. Minimum filling level.

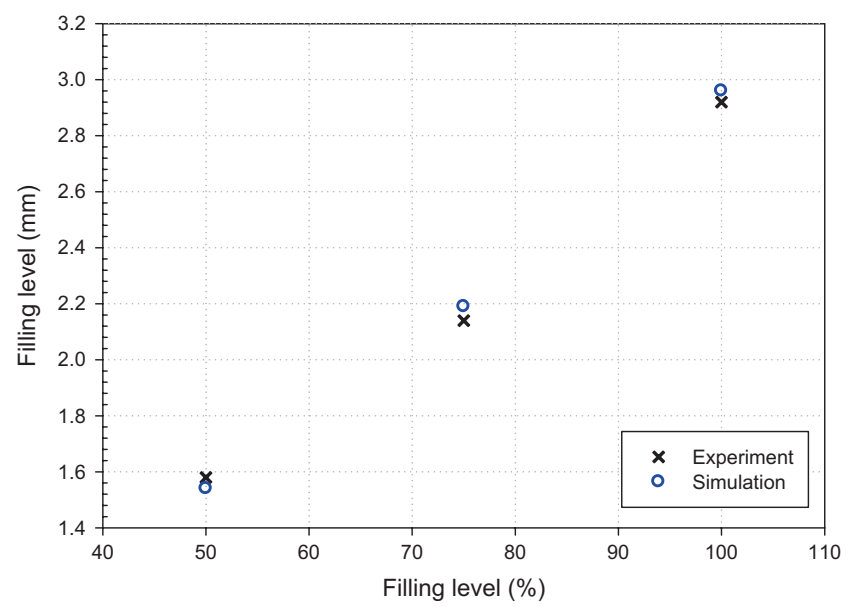

Figure 14. Maximum filling level. 


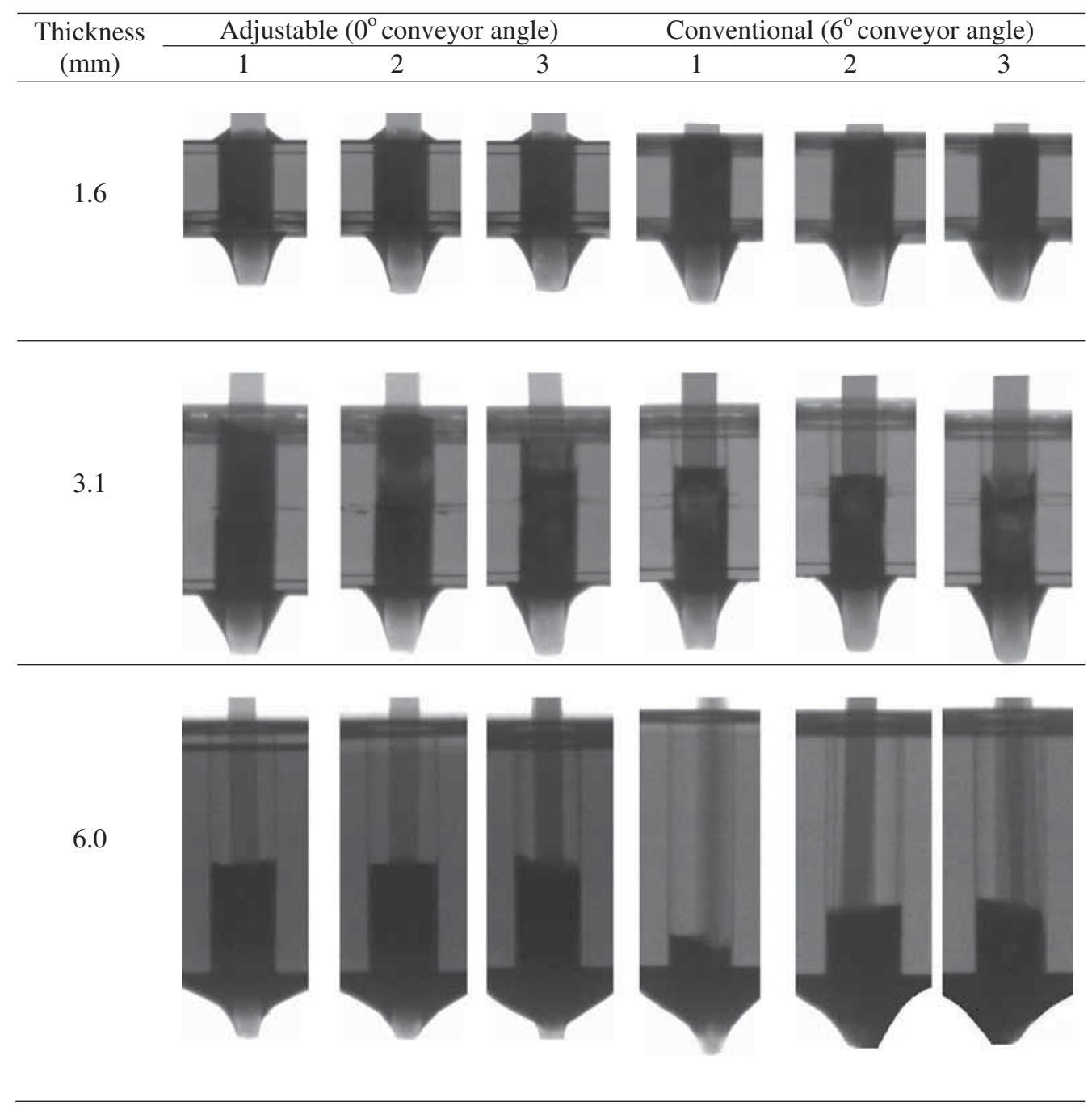

Figure 15. Vertical fill level (\%) of adjustable and conventional wave soldering machine.

Table 2. Average (\%) of vertical fill level for adjustable wave soldering machine (square pin).

\begin{tabular}{lcccc}
\hline PCB thickness $(\mathrm{mm})$ & 1 & 2 & 3 & Average \\
\hline 1.6 & $100.0 \%$ & $100.0 \%$ & $100.0 \%$ & $100.0 \%$ \\
3.1 & $86.2 \%$ & $94.5 \%$ & $72.7 \%$ & $84.5 \%$ \\
6.0 & $47.4 \%$ & $47.4 \%$ & $47.37 \%$ & $47.4 \%$ \\
\hline
\end{tabular}

in the PCB with a thickness of $3.1 \mathrm{~mm}$, a value that is considered acceptable for most electronic applications. However, nearly $50 \%$ of the PCB hole were filled with molten solder in the PCB with a thickness of $6.0 \mathrm{~mm}$. 
Table 3. Average $(\%)$ of vertical fill level for conventional wave soldering machine (square pin).

\begin{tabular}{lcccc}
\hline PCB thickness $(\mathrm{mm})$ & 1 & 2 & 3 & Average \\
\hline 1.6 & $91.0 \%$ & $91.2 \%$ & $94.8 \%$ & $92.3 \%$ \\
3.1 & $64.8 \%$ & $55.6 \%$ & $57.4 \%$ & $59.3 \%$ \\
6.0 & $13.7 \%$ & $29.3 \%$ & $30.0 \%$ & $24.3 \%$ \\
\hline
\end{tabular}

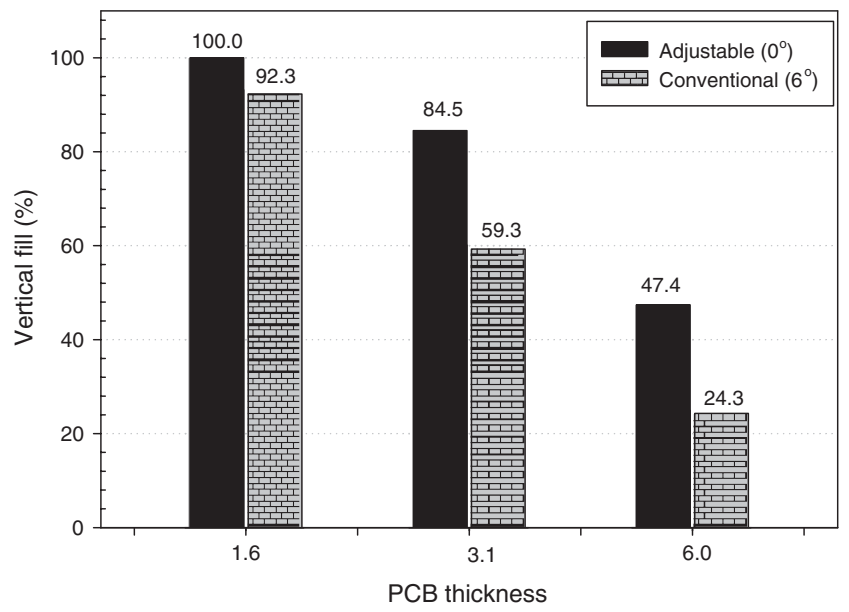

Figure 16. Comparison of vertical filling level (\%) at different PCB thickness (square pin).

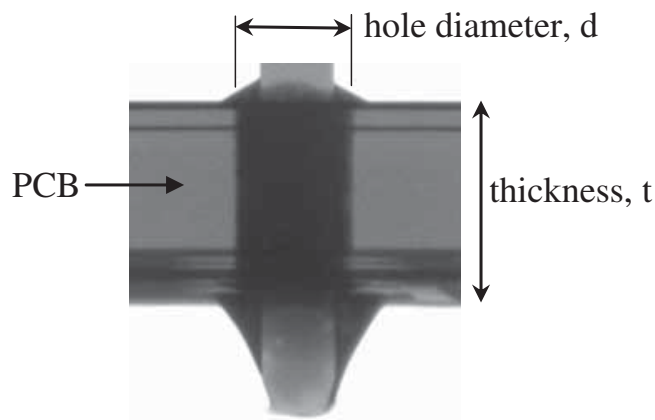

$$
\text { Aspect ratio }(A R)=\frac{\text { hole diameter }, d}{P C B \text { thickness }, t}
$$

Figure 17. Aspect ratio of the PCB.

Figure 16 shows that conventional wave soldering produced less vertical fill than adjustable fountain wave soldering for all three PCB thicknesses. No topside fillet was found in the PTH solder joint in the $1.6 \mathrm{~mm}$ thick PCB. The increase in PCB thickness $(3.1 \mathrm{~mm})$ significantly reduced the vertical fill; approximately $60 \%$ of the PCB hole were filled with solder. The vertical fill in the $6.0 \mathrm{~mm}$ thick PCB was very low $(24.3 \%)$. This result indicates that the effect of PCB thickness on the performance of vertical fill is enhanced when an adjustable wave soldering method is utilized. The vertical fills for both 3.1 and $6.0 \mathrm{~mm}$ thick PCBs are considered defective 
because they are lower than the minimum vertical fill of $75 \%$ stated in IPC-A-610D. Thus, optimum process setting is important to enhance the vertical fill of thick PCBs. Appropriate process parameters could significantly improve the vertical fill through adjustable fountain wave soldering method.

Besides, the aspect ratio of the PCB was also investigated. Figure 17 shows the aspect ratio of the PCB, which is the hole diameter $(d)$ divided by the PCB thickness $(t)$. The aspect ratio used in the experimental work is summarized in table 4. The experimental results (table 5) revealed the highest vertical fill level when smallest aspect ratio $(A R=2)$ is applied to both types of wave

Table 4. PCB sample at different aspect ratios.

\begin{tabular}{lcc}
\hline $\begin{array}{l}\text { PCB thickness, } \\
\mathrm{t}(\mathrm{mm})\end{array}$ & $\begin{array}{c}\text { Hole size, } \\
\mathrm{d}(\mathrm{mm})\end{array}$ & $\begin{array}{c}\text { Aspect ratio } \\
(\mathrm{AR})(\mathrm{t} / \mathrm{d})\end{array}$ \\
\hline 1.60 & 0.80 & 2 \\
3.10 & 1.03 & 3 \\
6.00 & 1.51 & 4 \\
\hline
\end{tabular}

Table 5. Average (\%) of vertical fill level for adjustable $0^{\circ}$ and conventional $6^{\circ}$ wave soldering machine $\mathrm{s}$ at different AR.

\begin{tabular}{lccc}
\hline AR & $\begin{array}{c}\text { Adjustable } \\
0^{\circ}(\%)\end{array}$ & $\begin{array}{c}\text { Conventional } \\
6^{\circ}(\%)\end{array}$ & $\begin{array}{c}\text { Differences } \\
(\%)\end{array}$ \\
\hline 2 & 100.0 & 92.3 & 7.7 \\
3 & 84.5 & 59.3 & 25.2 \\
4 & 47.4 & 24.3 & 23.1 \\
\hline
\end{tabular}

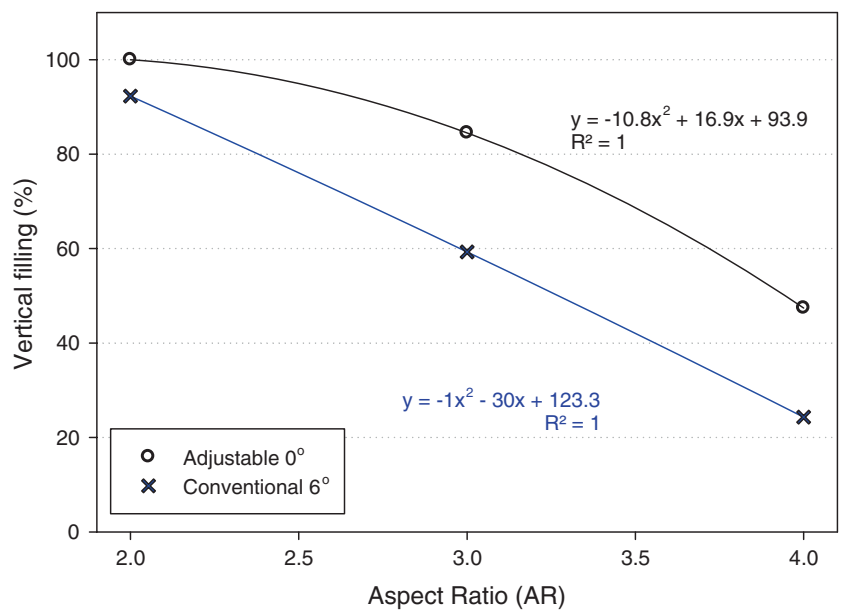

Figure 18. Vertical filling level versus aspect ratio of the PCB for adjustable and conventional wave soldering. 


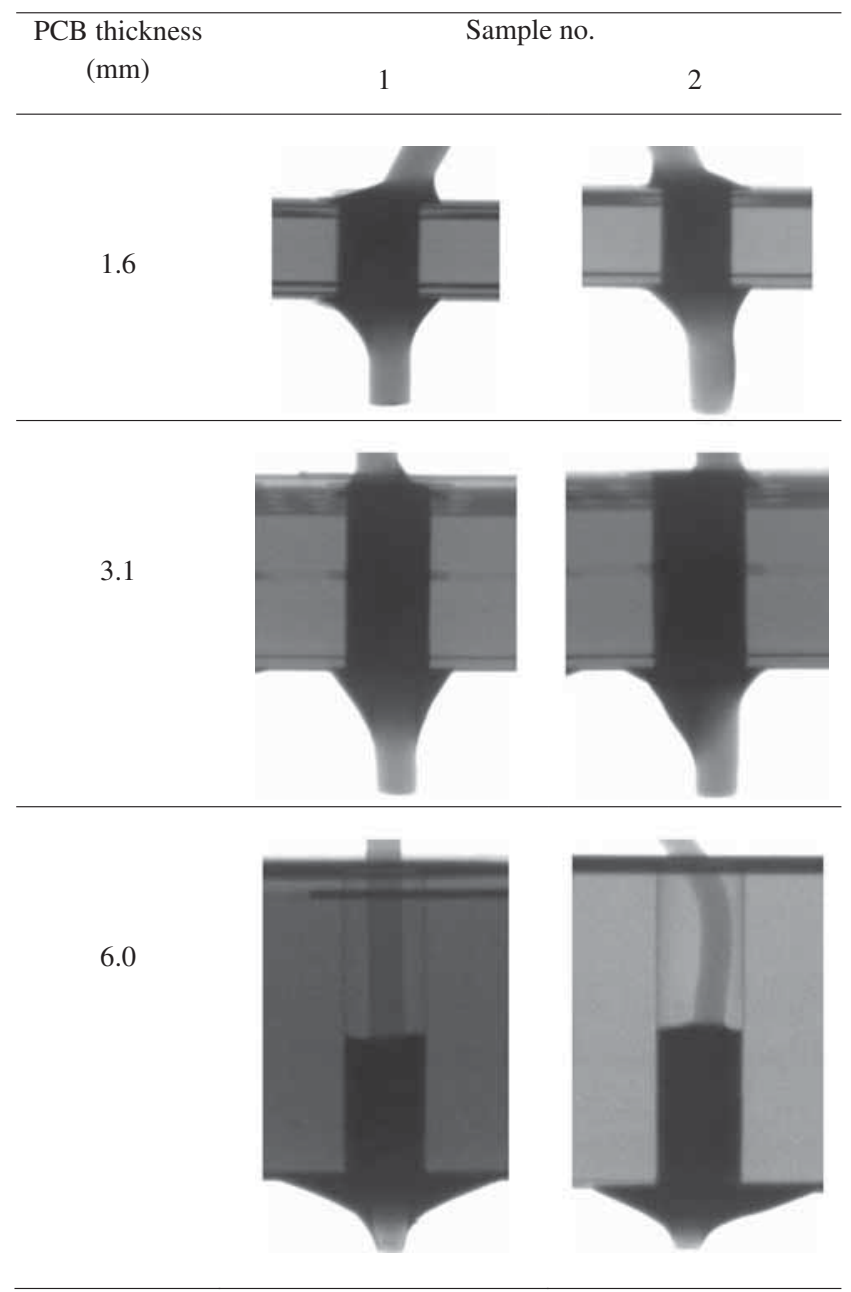

Figure 19. Circular PTH vertical fill using the adjustable wave soldering machine.

soldering process. The vertical fill level is decreasing, when the aspect ratio of the PCB rises to 3 and 4 . This indicated that the vertical fill level is crucially affected by the aspect ratio of PCB. The correlation between the percentage of vertical fill and the aspect ratio is illustrated in figure 18. From the results, the application of the adjustable wave soldering improved the vertical fill from the conventional wave soldering nearly $7.7 \%, 25.2 \%$ and $23.1 \%$ for the aspect ratio 2, 3 and 4, respectively. The experimental results revealed that application of adjustable wave

Table 6. Average (\%) of vertical fill level for adjustable fountain wave soldering (circular pin).

\begin{tabular}{lccc}
\hline PCB thickness $(\mathrm{mm})$ & 1 & 2 & Average \\
\hline 1.6 & $100 \%$ & $100 \%$ & $100 \%$ \\
3.1 & $90.4 \%$ & $88.5 \%$ & $89.5 \%$ \\
6.0 & $46.8 \%$ & $50.8 \%$ & $48.8 \%$ \\
\hline
\end{tabular}


Table 7. Differences of vertical fill level (\%) between circular and square pin.

\begin{tabular}{lccc}
\hline PCB thickness $(\mathrm{mm})$ & Circular & Square & Differences \\
\hline 1.6 & $100 \%$ & $100.0 \%$ & $0 \%$ \\
3.1 & $89.5 \%$ & $84.5 \%$ & $5 \%$ \\
6.0 & $48.8 \%$ & $47.4 \%$ & $1.4 \%$ \\
\hline
\end{tabular}

soldering process yielded better vertical fill than the conventional wave soldering method. Both experimental results were compared at different PCB thicknesses, while the PCB hole diameter and pin shape are considered as constant parameter. As mentioned in Section 3, the adjustable wave soldering machine has different methods to generate the fountain wave, where the solder wave height is adjustable (to improve the contact area with the PCB) compared with the conventional wave soldering machine. In figures 5 and 6 , the solder fountain can be controlled based on the PCB specifications. For example, two fountain waves from both pressure nozzles are generated for denser PCB hole, which enhance the contact area of the solder with the bottom PCB. However, the fountain wave height of the conventional wave soldering is difficult to control. Therefore, the experimental results showed better vertical filling compared with the conventional wave soldering machine.

\subsection{Effect of pin shape}

Figure 19 shows the selected samples of the circular pin solder joint after adjustable wave soldering. A phenomenon similar to the one discussed above was observed when a circular pin was used for PCBs with various thicknesses. The use of a circular pin has a minor effect on vertical fill as shown in table 6. The application of a circular pin produced a vertical fill of $100 \%, 89.5 \%$, and $48.8 \%$ for the $1.6,3.1$, and $6.0 \mathrm{~mm}$ thick PCB, respectively. The differences between the square and circular pin in the 3.1 and $6.0 \mathrm{~mm}$ thick PCB are only $5 \%$ and $1.4 \%$, respectively (table 7). The vertical fill level is plotted against PCB thickness in figure 20. The results show that the shape of the pin does not significantly affect the vertical fill in the adjustable fountain

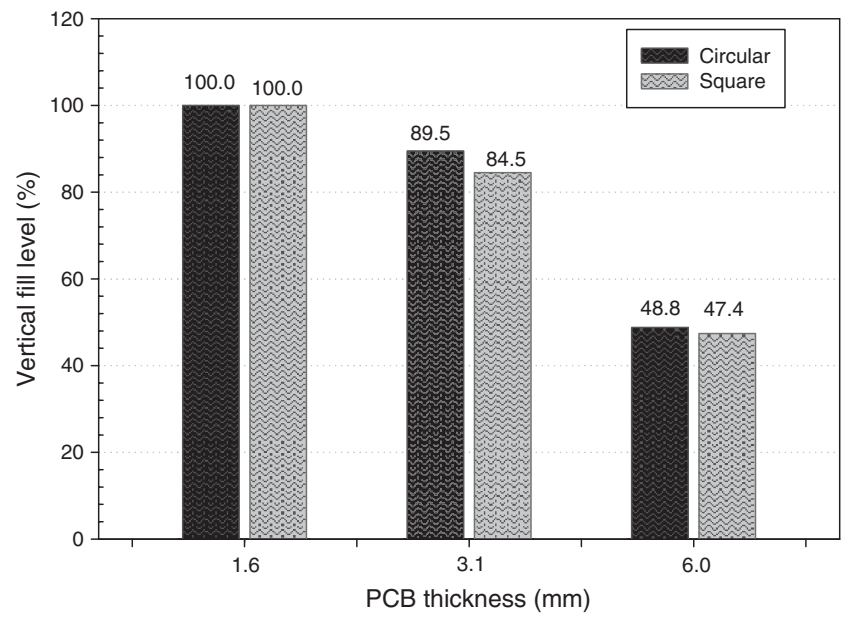

Figure 20. Average vertical fill level (\%) for circular and square pin shape. 
Table 8. Average (\%) of vertical fill level at different AR for adjustable fountain wave soldering.

\begin{tabular}{lcc}
\hline AR & Square (\%) & Circular (\%) \\
\hline 2 & 100.0 & 100 \\
3 & 84.5 & 89.5 \\
4 & 47.4 & 48.8 \\
\hline
\end{tabular}

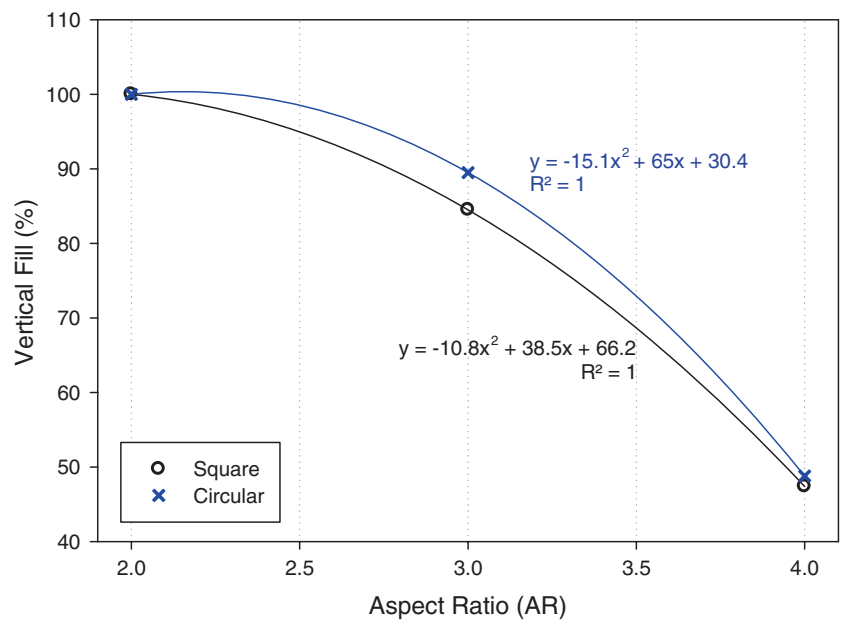

Figure 21. Vertical filling level versus aspect ratio of the PCB for square and circular pin.

wave soldering process. The use of square and circular pin also influences the vertical fill level for different aspect ratios in the adjustable fountain wave soldering process. The experimental results are summarized in table 8 . Both square and circular pin demonstrate highest vertical fill for smallest aspect ratio $(A R=2)$. The vertical fill level decreases when the increase in aspect ratio. However, the vertical fill was slightly affected by the pin shape at different aspect ratios. The differences of the vertical fill for both pin shapes are less than $6 \%$. The circular pin has $5 \%$ of vertical fill higher than square pin at an aspect ratio $(A R=3)$. This scenario is clearly observed in figure 21. Moreover, angle-edged PTH, such as triangular and hexagonal PTH, can affect surface tension and adhesive force, which in turn increase the filling time and result in an uneven profile (Abdul Aziz et al 2014c) during wave soldering.

\subsection{Voiding in the PTH solder joint}

The presence of voids may cause cracks to occur in the solder joint under a thermal cycling condition (Nguyen et al 2009). Therefore, minimizing voids in the solder joint is always a concern in the electronics assembly industry. The presence of voids in the PTH solder joint may be attributed to several factors, such as pin-to-hole ratio (Nguyen et al 2009), PTH plating, improper conveyor speed, preheating time, and intermetallic outgassing. Typically, the void formation is due to the moisture entrapment, and outgassing during the wave soldering process (Alpha 2011); hence, it forms the void in the PTH solder joint. Besides, too much flux on the PCB that not evaporates (or drying off) during the pre-heating stage leads to the outgassing and creates voids. 


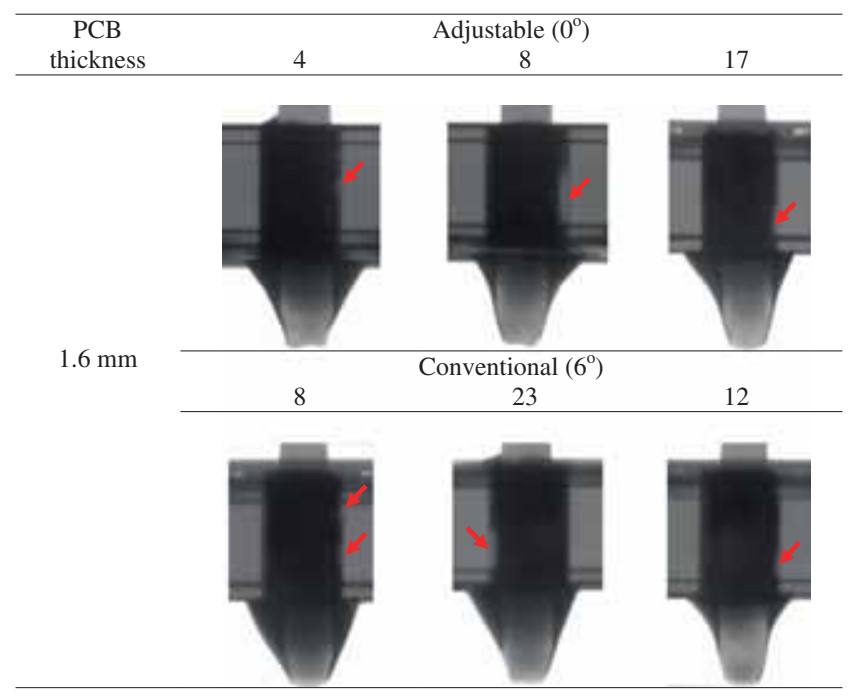

Figure 22. Void formation of $1.6 \mathrm{~mm}$ PCB thickness.

Other factors such as improper plating of the PCB and poor solderability due to oxidation will also cause the void formation. Therefore, the effect of PCB thickness on the void in the PTH solder joint was also investigated. Figure 22 shows an example of a PTH solder joint (1.6 mm PCB

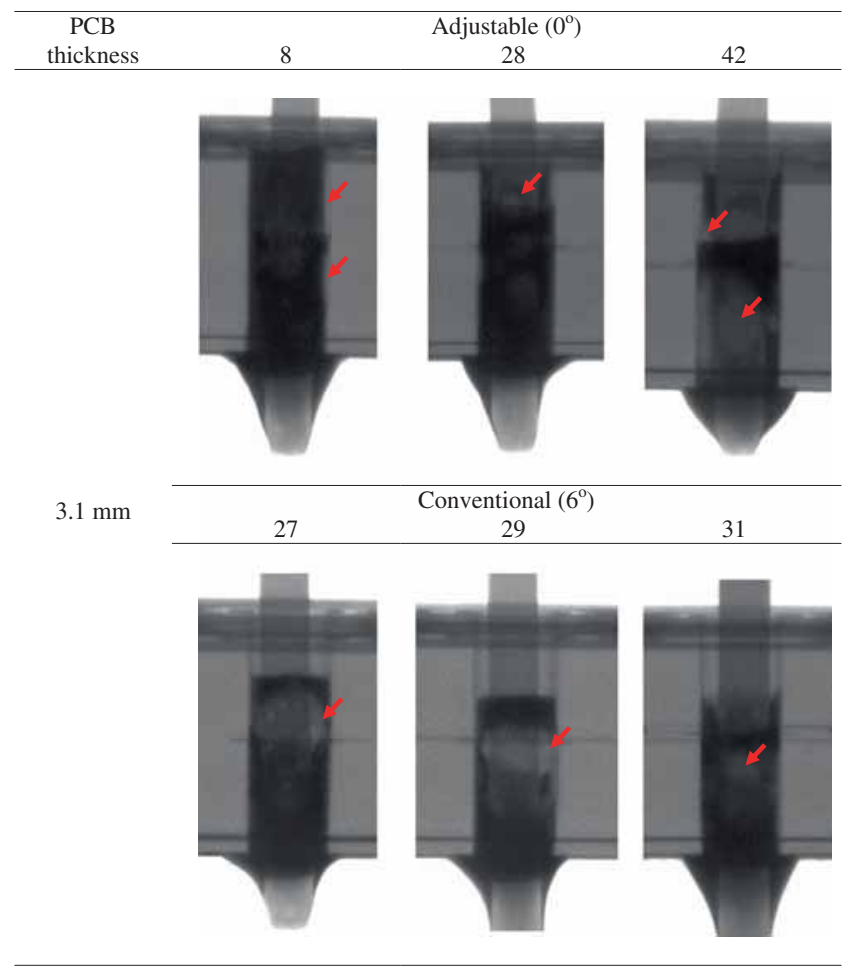

Figure 23. Void formation of $3.1 \mathrm{~mm}$ PCB thickness. 
thickness) for the two methods. The arrows point to the void in the solder joint. In the $1.6 \mathrm{~mm}$ thick PCB, small voids can be found in regions close to the PCB hole surface. The PTH solder joints of the two wave soldering methods have almost the same void size as shown in figure 22 . The experimental results reveal that a thick PCB produces large voids in the PTH solder joints (figure 23). The voids in the conventional wave soldering-assembled PTH (at $3 \mathrm{~mm}$ thickness) are larger than those in the PTH soldered by adjustable fountain wave soldering. Figure 24 shows the PTH solder joint of the $6 \mathrm{~mm}$ thick PCB assembled by adjustable fountain wave soldering. Small void size was observed around the pin.

Figure 25 shows an experimental sample of an offset pin in the PCB through-hole after wave soldering. The components in the figure are clearly labeled. The void in the solder material formed close to the surface of the PCB hole, and no crack was found around the void region. Figures 26 and 27 show the void and stain found in the sample. The stain of the PCB throughhole was identified and created during sample preparation. The void size depicted in figure 26 is larger than the void size in figure 27. Large voids or excessive numbers of voids may affect the integrity of the solder joint and thus cause failure in the electric connection. Voids may also increase the stress on the solder joint, facilitate crack, and affect the joint's capacity to withstand low cycle fatigue. To eliminate the void formation in the PTH solder joint, a few criteria must be concerned such as contamination in the PCB hole, entrapped fluid by the component, and outgassing of moisture that entrapped in the PCB during the wave soldering (Alpha 2011). Therefore, proper control of several parameters, such as board contamination, oxide content of

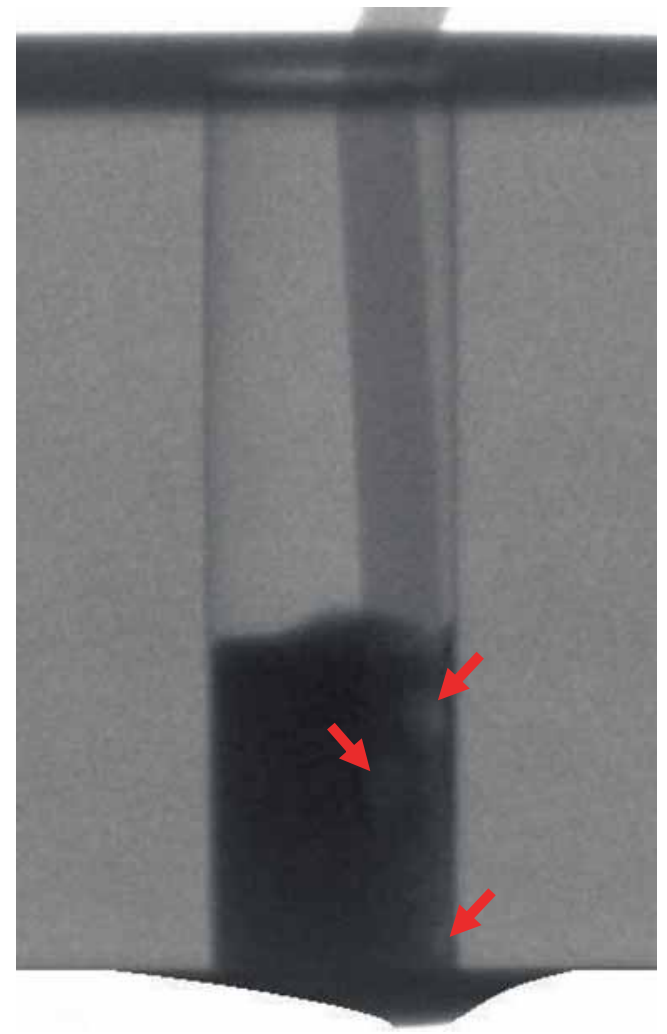

Figure 24. Void formation of $6.0 \mathrm{~mm}$ PCB thickness for adjustable wave soldering. 

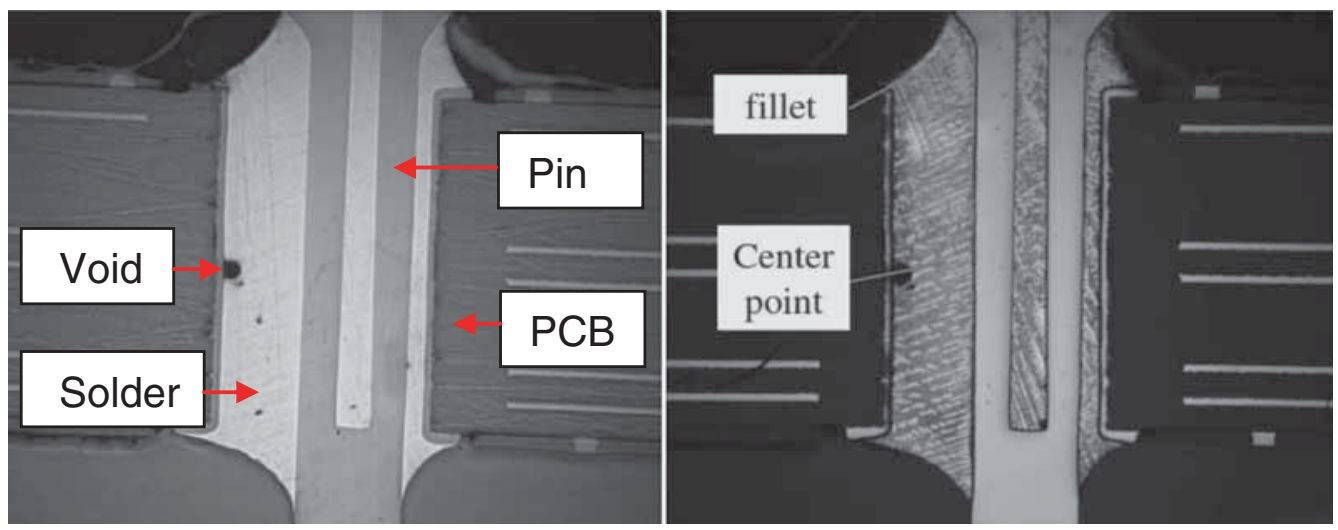

Figure 25. Void formation of pin assembly.

the soldered surface, and surface finish of $\mathrm{PCB}$, is important to minimize voids in the PCB through-hole during wave soldering. Several recommendations can be considered during the wave soldering process to attain better soldering quality based on the experimental results. The adjustable fountain wave soldering technique yields better vertical fill compared to the conventional wave soldering machine. This is because high energy fountain wave from the adjustable wave soldering machine improves the vertical filling process. Besides, proper control of dwell time (contact time for molten solder and $\mathrm{PCB}$ ) and temperature of the topside board is important to obtain better vertical fill, and topside fillet. Soldering temperature plays a crucial role in the vertical filing. Insufficient or too low solder temperature causes the molten solder cool and solidifies in the PCB hole before it reaches the top side, this phenomenon can be observed when

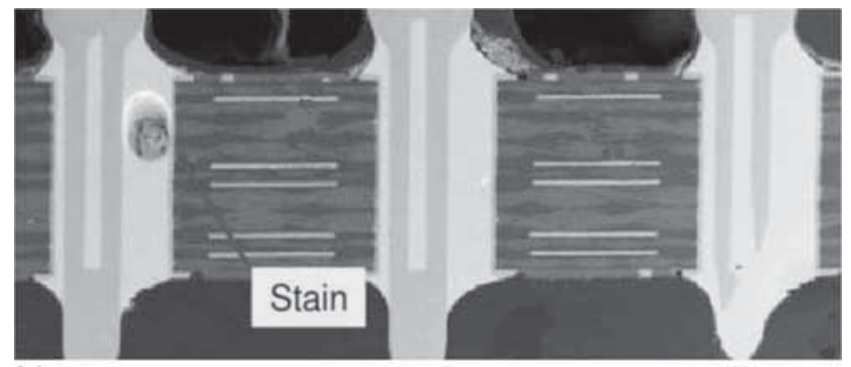

(a)

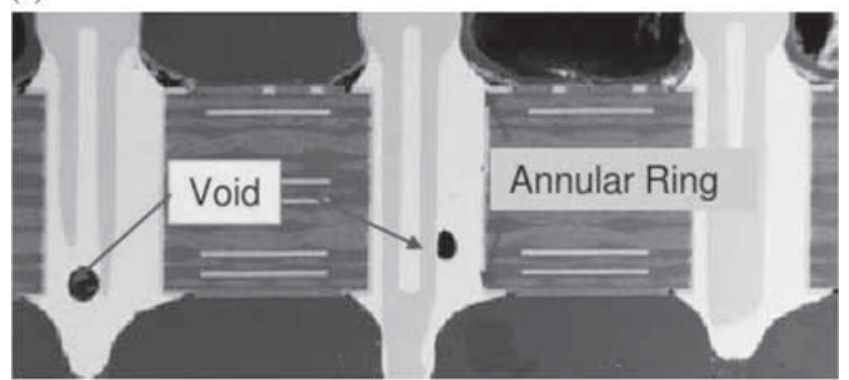

(b)

Figure 26. Stain and void formation for offset pin position. 


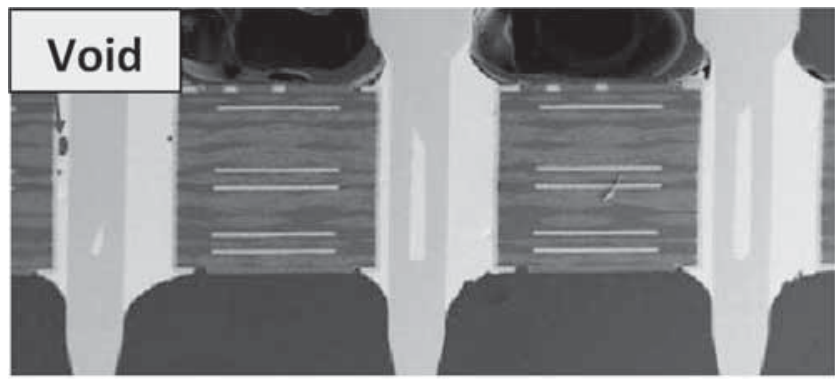

(a)

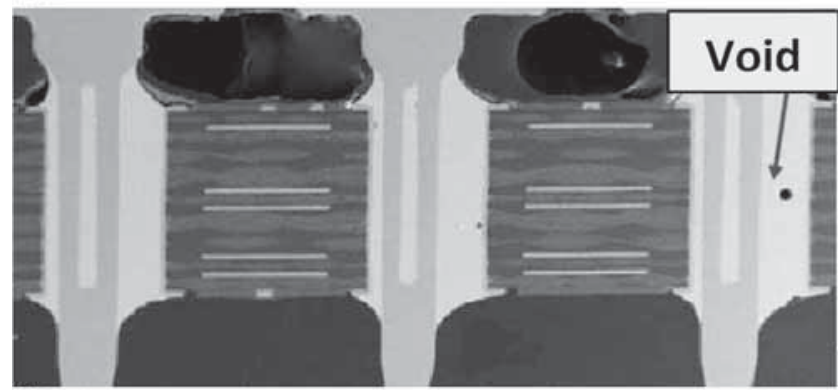

(b)

Figure 27. Void formation in PCB through-hole for offset pin position.

using the thicker PCB. Therefore, the control of process parameters is significant to obtain the best quality of PTH solder joint during the wave soldering process.

\section{Conclusions}

An experimental investigation was conducted on the effects of PCB thickness on adjustable fountain and conventional wave soldering. The PTH vertical fills for 1.6, 3.1, and $6.0 \mathrm{~mm}$ PCB thickness were examined with an X-ray CT scan machine. The vertical fill for the three PCB thickness values, the pin shapes, and voiding was discussed. The experimental results reveal that PCB thickness significantly influences vertical fill. An increase in PCB thickness and aspect ratio reduces the percentage of vertical fill. The wave soldering method employed also affects the percentage of vertical fill. Adjustable fountain wave soldering process $\left(0^{\circ}\right.$ conveyor angle) yields a higher vertical fill than conventional wave soldering $\left(6^{\circ}\right.$ conveyor angle) for all three PCB thickness values. The vertical fills of adjustable fountain wave soldering for thickness of 1.6, 3.1, and $6.0 \mathrm{~mm}$ are $100 \%, 84.5 \%$, and $47.4 \%$, respectively. Vertical fills of only $92.3 \%, 59.3 \%$, and $24.3 \%$ were obtained when conventional wave soldering was employed. The results indicate that a molten solder can easily fill a PCB hole at a conveyor angle of $0^{\circ}$. The differences in vertical fill level for both circular and square when using different PCB thicknesses (1.6 mm, $3.1 \mathrm{~mm}$ and 6.0 $\mathrm{mm}$ ) were $0 \%, 5 \%$ and $1.4 \%$, respectively. Pin shape has an insignificant effect on vertical fill in adjustable fountain wave soldering. The results also reveal the difficulty in obtaining a vertical fill of $100 \%$ and the problem of large voids in thick PCBs. The experimental and simulation results show a reasonable agreement, with only $4.96 \%$ and $2.08 \%$ discrepancies for the maximum and minimum vertical fill levels, respectively, in adjustable fountain wave soldering. 


\section{Acknowledgements}

The author gratefully acknowledges the financial support of the Ministry of Higher Education of Malaysia through the My Brain 15 Ph.D. scholarship program, and technical supports from Shenzhen Kunqi Xinhua Technology Co., Ltd. (China) and Institute of Microengineering and Nanoelectronics (Malaysia).

\section{References}

Abdul Aziz M S, Abdullah M Z, Khor C Y and Che Ani F 2013 Influence of pin offset in PCB through-hole during wave soldering process: CFD modeling approach. Int. Commun. Heat Mass Transfer 48: 116123

Abdul Aziz M S, Abdullah M Z and Khor C Y 2014a Influence of PTH offset angle in wave soldering with thermal-coupling method. Soldering Surface Mount Technol. 26(3): 97-109

Abdul Aziz M S, Abdullah M Z, Khor C Y, Fairuz Z M, Iqbal A M, Mazlan M and Mat Rasat M S 2014b Thermal fluid-structure interaction in the effects of pin-through-hole diameter during wave soldering. Adv. Mech. Eng. 2014: 1-13

Abdul Aziz M S, Abdullah M Z, Khor C Y, Jalar A and Che Ani F 2014c CFD modeling of pin shape effects on capillary flow during wave soldering. Int. J. Heat Mass Transfer 72: 400-410

Alpha 2011 Wave soldering troubleshooting guide. Cookson Electronics, 10/11 SM1071, 1-20. www.alpha. cooksonelectronics.com

Balachandran S 2012 Surfactant analysis of thin liquid film in the human trachea via application of volume of fluid (VOF). Fluid dynamics, computational modeling and applications ISBN: 978-953-51-0052-2., pp. 449-462

Huang C-Y, Huang H-H and Ying K-C 2012 Sn-Cu-Ni soldering process optimization using multivariate analysis. IEEE Trans Components Packaging Manuf. Technol. 2(3): 527-535

IPC-A-610D 2005 Acceptability of electronic assemblies, through-hole technology, Chapter 7, 39-40

Inagaki K, Nakagawa S, Hatakeyama T, Ishikura K and Koizumi K 2013 CFD simulation of wave soldering process (case of simple 2-dimensional configurations). In: Proceedings of ASME 2013 International Technical Conference and Exhibition on Packaging and Integration of Electronic and Photonic Microsystems, InterPACK 2013; Burlingame, CA; United States

Khor C Y, Abdullah M Z and Leong W C 2012a Fluid/structure interaction analysis of the effects of solder bump shapes and input/output counts on moulded packaging. IEEE Trans. Components Packaging Technol. 2(4): 604-616

Khor C Y, Abdullah M Z, Tony Tan H J, Leong W C and Ramdan D 2012b Investigation of the fluid/structure interaction phenomenon in IC packaging. Microelectron. Reliab. 52: 241-252

Kuo C-H, Hua H-H, Chan H-Y, Yang T-H, Lin K-S and Ho C-E 2013 Interfacial reaction and mechanical reliability of PTH solder joints with different solder/surface finish combinations. Microelectron. Reliab. 53(12): 2012-2017

Liukkonen M, Havia E, Leinonen H and Hiltunen Y 2009 Application of self-organizing maps in analysis of wave soldering process. Expert Syst. Appl. 36(3): 4604-4609

Liukkonen M, Havia E, Leinonen H and Hiltunen Y 2011 Quality-oriented optimization of wave soldering process by using self-organizing maps. Appl. Soft Comput. 11(1): 214-220

Nguyen J, Geiger D, Rooney D and Shangguan D 2009 A study of thermo-mechanical reliability of leadfree PTH solder joints. Soldering Surface Mount Technol. 21(2): 39-47

Pietraszek J, Gadek-Moszczak A and Toruński T 2014 Modeling of errors counting system for PCB soldered in the wave soldering technology. In: Proceedings of 8th International Conference on Terotechnology; Kielce; Poland, 874, 139-143

Puttlitz K J and Stalter K A 2004 Handbook of lead-free solder technology for microelectronic assemblies, CRC Press 
Ramdan D, Abdullah M Z, Khor C Y, Leong W C, Loh W K, Ooi C K and Ooi R C 2012 Fluid/structure interaction investigation in PBGA packaging. IEEE Trans. Components Packaging Technol. 2(11): 17861795

Suganuma K, Ueshima M, Ohnaka I, Yasuda H, Zhu J and Matsuda T 2000 Lift-off phenomenon in wave soldering. Acta Mater. 48(18-19): 4475-4481

Wang W, Peng Y and Wang X 2011 Key parameter optimization in wave soldering. Adv. Mater. Res. 323: $84-88$

Wang J, Wei X, Zhu W, Wu J and Wu N 2013 Study on low silver Sn-Ag-Cu-P alloy for wave soldering. In: Proceedings of 20th IEEE International Symposium on the Physical and Failure Analysis of Integrated Circuits, IPFA 2013; Suzhou; China, 485-489

Yapici H, Basturk G, Kayatas N and Yalcin S 2005 Numerical study on transient local entropy generation in pulsating turbulent flow through an externally heated pipe. Sadhana Acad. Proc. Eng. Sci. 30(5): 625648

Yazdi J, Sarkardeh H, Azamathulla H Md and Ghani A Ab 2010 3D simulation of flow around a single spur dike with free-surface flow. Int. J. River Basin Manag. 8(1): 55-62 